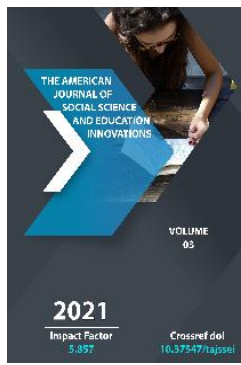

\section{Methodological Tasks In The Procedure Of Pedagogical Activity Of A Special Teacher}

\author{
Sattorova Mohira Aminqulovna \\ Teacher Of Karshi State University, Karshi City, Uzbekistan \\ Kurbanova Aziza Uktamovna \\ Teacher Of Karshi State University, Karshi City, Uzbekistan
}

Journal Website:

http://theamericanjour

nals.com/index.php/taj

ssei

Copyright: Original content from this work may be used under the terms of the creative commons attributes 4.0 licence.

\title{
ABSTRACT
}

This article describes the essence of issues such as methodological tasks in the field of pedagogical activity of special teachers, their content in the development of professional competence of the specialist.

\section{KEYWORDS}

Methodical competence, pedagogical activity, methodical tasks, general procedure in activity, methodical activity, teacher

\section{INTRODUCTION}

The development of professional competence of any specialist is uneven and cyclical. As part of the preparation of a student in the educational process, the emphasis should be shifted to the formation of professional competence in the form of educational 
competencies. Investigating the methodological direction of the work of a special teacher (teacher-defectologist), it is necessary to highlight and describe methodological competencies as the ability to carry out a specific type of professional activity, to characterize the methodological task as the main unit (determinant) of methodological activity.

The formation and development of methodological competencies in the process of professionalization occurs as a result of familiarization, assimilation and appropriation of methodological activities by the future special teacher. In the literature, it is presented as a type of pedagogical (A.A. Verbitsky, N.V. Kuzmina, etc.). Analysis of studies revealing an activity-based approach to the professional training of teachers allows us to characterize pedagogical activity as the teacher's activity in solving a variety of pedagogical problems aimed at developing and

Training of the younger generation (N.V. Kuzmina, L.M. Mitina, Yu.N. Kuljutkin, G.S. Sukhobskaya, etc.). Consequently, methodological activity includes the necessary knowledge, skills and methods of performing actions, which are aimed at solving an infinite number of methodological problems. The originality of this type of activity is associated with the concepts of "methodology", "teaching methodology". Analysis of the term "methodology" in pedagogical dictionaries and psychological and pedagogical studies of the teacher's professional activity (including special teacher) allows us to characterize methodological activity in a broad sense as a "procedural picture" of a certain type of activity. This is a full range of actions, which includes: analysis of the necessary conditions for the situation of activity, goal setting, planning, programming (actions in activities or operations in action), execution, control and evaluation of results (I.M. Yakovleva, N.V. Kuzmina, etc.) [4, 9]. Narrow meaning (teaching methodology) is a system of pedagogical (methodological) actions aimed at teaching, upbringing and development of a child within a certain area of knowledge (conditionally a subject). At this level, methodological activity retains a procedural component, but is considered in relation to a clearly defined subject situation and a specific group of students (the method of teaching mathematics in elementary school, the method of teaching Russian to schoolchildren with severe speech impairment, etc.). In this regard, the methodological competencies of a special teacher include knowledge, understanding, assessment of their own actions (within the framework of solving methodological problems) and the ability to perform them qualitatively in situations of learning, correction and development of children with disabilities $(\mathrm{HH})$ through the content of academic subjects (educational areas ). The key to understanding them is a complex of pedagogical actions, an implementation procedure in relation to the subject area of knowledge.

In accordance with the general procedure of activity (S.L. Rubinshtein, A.N. Leontyev, P.Ya. Galperin, etc.), pedagogical is implemented in a number of links: motivational-orientational, executive, control-evaluative and includes the following procedural components: pedagogical goals and objectives, the choice and application of the means of influencing the student, the teacher's control and assessment of their influences (N.V. Kuzmina, A.K. Markova, L.M. Mitina, etc.).

The first component is characterized by the specificity of pedagogical goals and objectives, which are related as general and particular. A pedagogical task is a goal set in a specific situation. There are several approaches to defining its essence: informational, problematic, general (GA Ball, AV Brushlinsky, AM Matyushkin, MM Makhmutov, V. Okon, D. Poya, Ya.A. Ponomarev, L.M. Fridman and others). The 
essence of the task from the activity position is defined as the determinant of action, the main component (element) of the structure of activity (S.L. Rubinstein, A.N. Leontyev, G.S.Kostyuk, etc.). In psychology, the general concept of "task" sounds like a combination of the subject's goal and the conditions in which it must be achieved. In pedagogical research (I.K.Zhuravlev, V.I. Zagvyazinsky, I.Ya. Lerner, etc.), a task is an elementary unit of the pedagogical process, a materialized situation of education and training, characterized by the interaction of a teacher and a student with a specific purpose. The most deeply, in our opinion, this problem is revealed in the psychological and pedagogical theory of problems of G.A. Balla [1]. The author distinguishes the task from the problem situation as a certain set of objects that admits a systemic representation in the form of a task, but has not yet received it; from the symbolic model of the problem, in particular, its verbal formulation; from the meaning of this model, i.e. the information that it carries about the task. The solution of the problem is the impact on the object of the problem, which determines its transition from the initial state to the required one. Mixing tasks by type requires the separation of the subject of the task, since the types are distinguished, first of all, based on the properties of its subject. So, cognitive is aimed at improving knowledge and cognitive activity, educational - at the formation of educational actions, etc. Consequently, the methodological task is to form methodical actions.

The specificity of pedagogical tasks has been highlighted in numerous studies (Z.A. Abasov, N.V. Bordovskaya, N.V. Kuzmina, Yu.N. Kuljutkin, G.S. Sukhobskaya, A.K. Markova, A.I. A.A. Rean, L.F.Spirin, etc.) and is characterized by a connection with the implementation of learning functions, the presence of a diverse combination of conditions for interaction between a teacher and students, requires the choice of certain professional actions, has a variety of solutions. So, A.K. Markova identifies the following general features of pedagogical tasks [5]:

- Its subject is a characteristic of the child's mental development, therefore, it should include his initial state and the model of the required state;

- The statement of the problem should take into account the child as an "active and equal participant in the educational process", in this regard, the fact of changing the task as a result of its "redefinition" or "redefinition" by the student should be taken into account (G.A. Ball, V.V. . Davydov, V.V. Repkin and others);

- Solving a problem requires immediate action in a pedagogical situation, and the result is almost always delayed in time;

- There is a hierarchy of pedagogical tasks: from global, strategic, which society sets for the teacher, to the tasks set by the content of the subject and further to the set contingent of the class and determined by the teacher himself.

The term "methodological problem" is found in the literature, but is more often considered in relation to the study of issues of a particular subject methodology and research is more of a practical nature [7]. Theoretical research that reveals the scientific essence and features of methodological tasks is not enough, which is associated with considering them as a type of pedagogical task. In our study, we pay close attention to them because of the high importance of the methodological direction of pedagogical work (AA Verbitsky and others), as well as the role of methodological tasks in the formation and improvement of professional competencies of future special teachers [3]. The peculiarity of the methodological task follows, in the opinion of scientists, from the specific 
characteristics of the learning process itself in the subject methodology, which demonstrates the mediation of the interaction of subjects of education by the subject area of knowledge (teacher - subject - student), which will affect the content of the task and the methods of its solution [2, 8 ].

Genetically, the starting point for the emergence of a problem is a problem situation as a result of the analysis and assessment of a set of conditions for a pedagogical situation. VI Zagvyazinsky calls it the initial structure of the pedagogical process. L.F. Spirina's pedagogical situation is an objective state of the pedagogical system, considered in a certain time interval, the result of its analysis is the formulation of a pedagogical task. N.V. Kuzmina - the real situation in a group of students, as a complex system of their relationships and relationships, which must be taken into account when making a decision. S.Yu. Temina is a separately taken moment of the educational process, characterized by a system of all kinds of relationships between its participants. As you can see, the definitions presented in the works of different authors have a general meaning, in which the situation appears as a moment of the pedagogical process, which is a set of certain conditions and is characterized by a complex system of relationships between its participants. In addition, what is especially important, it constitutes the main procedural characteristic of the pedagogical process, is a micro-cell of pedagogical activity and pedagogical training of the future teacher, since it is in it that a contradiction arises between the desired effect of influencing the student's personality and the effect that is actually achieved. This contradiction gives rise to a problem on the basis of which a specific pedagogical task is formulated, which can be solved only as a result of an analysis of the conditions prevailing in the situation. The primacy of the situation is also presented in the stages of solving the pedagogical problem (N.V. Kuzmina): analytical - begins with the analysis and assessment of the current situation and ends with the formulation of the pedagogical problem itself to be solved; projective stage - ways of solving the already posed pedagogical problem are planned, a specific "project" of this solution is being developed; performing - associated with the implementation of the concept, with the practical implementation of the developed "project". In this regard, pedagogical tasks not only solve a certain kind of problem situations, but also are a means that allows one to predict typical situations that arise in the real practice of a teacher's professional activity, which is extremely important in organizing pedagogical training of students (V.P. Bespalko, N. V. Kuzmina, Yu.N. Kuliutkin, V. Okon, V.V.Serikov and others).

The methodological situation is also specific, the analysis of which should, in our opinion, include not only the primary analysis of the characteristics of the child's development, his general condition, pedagogical components of the impact, but also the specifics of the academic subject or complex of disciplines. With regard to the problem of our research, it can be considered from different positions: the availability of the presented content of the academic subject for a child with disabilities, the degree of focus (correctional, educational, upbringing), practical significance, emotional impact, etc. In addition, the subject determinism of the named sides should be noted. analysis, for example, when assessing the child's position in a situation, it is important to consider the motivation for the child's study of the subject, the choice of pedagogical components is also not possible without taking into account the subject specificity.

So, in the procedure for the implementation of pedagogical activity, the analysis of the conditions of the pedagogical situation is initially carried out, the problem is singled out, on the basis of which the pedagogical task is formulated, its solution is planned and 
programmed. Further, pedagogical activity moves on to the next component - the choice and use of means of influencing the student or the choice and use of means and methods for solving a pedagogical problem. The most complete, in our opinion, the selection conditions are presented in the work of L.M. Mitina, where the priority is to focus on the student as the central figure of the pedagogical process. Secondly, the orientation towards the choice and application of pedagogical methods and methods of self-realization, the manifestation of the personal qualities and capabilities of the teacher, necessary in working with children. Thirdly, the focus on the selection and processing of the content of educational material in order to form a system of knowledge, the connection between the subject and life; selection of such necessary components as auxiliary, illustrative, informational. Fourth, orientation towards the choice and application of methods and forms of organizing interaction with students and students with each other; creating conditions that facilitate the learning process, an atmosphere of live communication, a positive emotional and psychological climate [6, p. 29]. A.K. Markova names three main groups of influences on the student as a means of controlling the mental development of schoolchildren. They correspond to the generally accepted "what to teach", "whom to teach" and "how to teach" [5]: selection, processing by the teacher of the content of the educational material; study of the available opportunities of students and new levels of their mental development; selection and application of methods, forms, means of influence and their combinations. The author gives their systematization.

In our opinion, the specificity of methodological activity in general and of a special teacher in particular sets somewhat different accents in terms of choosing a method of influence. Emphasizing, following L.M. Mitina, the primary focus on the student (and in special education - a systematic, complete picture of him, his opportunities and special needs), in second place we attribute the selection, analysis and processing of the subject content (its correctionaldevelopmental, socializing, upbringing and educational purpose) and only then the selection of pedagogical components.

The third component of pedagogical activity is the teacher's control and assessment of his influences - the stage of diagnosis. It is aimed primarily at predicted changes in the development of the child. Secondly, on the awareness and correction of one's work (focus on oneself) - the study of the level of one's skill, through the analysis of the procedural and effective aspects of labor self-analysis [5]. L.M. Mitina distinguishes two variants of analysis: the subject is separated from the object of analysis and the subject is the object of analysis (introspection). According to the authors, a correctly conducted analysis is a source of professional development as "a way to reveal the essence of specific pedagogical phenomena in order to obtain information necessary to optimize the educational process" [6, p. 31]. It is based on the teacher's awareness of the relationship between the components of pedagogical activity, the relationship between the tasks, means, solutions, and expected results.

Thus, pedagogical activity in accordance with the general structure of activity includes indicative, executive and control phases, in accordance with which three components of its structure are distinguished: setting pedagogical goals and objectives, choosing and using means of influencing the student, control and assessment by the teacher of his influences. A.K. Markova notes that pedagogical activity requires the implementation of all the listed components at an expanded and high level.

Research in the field of studying methodological activity, its systemic vision, 
generalized content, integral procedure, etc. is not enough, but the basis is work in the field of pedagogical activity. In this regard, methodological activity is the solution of an infinite set of methodological problems aimed at developing and teaching the younger generation through the content of a specific subject area of knowledge.

Consequently, methodological competencies, as the ability to carry out methodological activities, should reflect the procedure for its implementation and include the necessary knowledge, skills and methods of performing actions that are aimed at analyzing methodological situations and solving methodological problems (understanding the problem, formulating the problem, choosing ways of solving, implementing, monitoring and evaluation of the result).

Subject determinism of methodological activity should be traced in the tasks. In this regard, the analysis of methodological situations should go from a complete understanding of the child as a subject of the educational process to the analysis and processing of the subject content. For a special teacher, this is the allocation and emphasis on the correctional, developmental and socializing orientation of the content (according to the special educational needs of the child), its upbringing and educational purpose; processing and construction of the material in accordance with the principles of selection of educational content for children with disabilities. And only then analysis and selection of the necessary pedagogical (methodological) components for the implementation of the educational process. Their choice is similarly substantively conditioned. So, the selection of the form of organization of training, the peculiarities of its structuring when teaching a particular subject is specific. For example, in a mathematics lesson (especially for younger school age), oral counting is included, in a literacy lesson, articulatory gymnastics, a geography lesson, familiarization with the world around them, etc. can take the form of an excursion, etc. The choice of the teaching method, according to the authors, will be justified only if it does not contradict the research method used in science, corresponds to its methodology (S.E. Kamenetskiy, N.S.Purysheva, A.S. Kondratyev, A.I. Khodanovich, S.E. Popov). The funds should reflect the subject of the scientific field of knowledge, regardless of the level of its representation in the training course.

So, a methodological task is a key link in methodological activity (determinant). It is aimed at performing methodological - subjectbased pedagogical actions. Consequently, the methodological competencies of a special teacher include knowledge, understanding, assessment of one's own actions (within the framework of solving methodological problems) and the ability to perform them qualitatively in situations of learning, correction and development of children with disabilities $(\mathrm{HH})$ through the content of academic subjects or educational areas.

The formation and development of the methodological competencies of the future special teacher is associated with the assimilation of these actions, the development of a general method of action in the methodological situations of teaching children with disabilities. In this regard, the procedure for the formation of competencies should be based on a system of methodological tasks, as "moments" of the pedagogical process, which should be traced when they are jointly solved by the teacher and students.

\section{REFERENCES}

1. Ball G.A. Theory of educational tasks [Text]: psychological and pedagogical aspect / G.A. Ball. - M.: Pedagogika, 1990 .-$183 \mathrm{p}$. 
2. Gladun L. A. Theoretical study of the concepts of pedagogical and methodological competence, competencies / L. A. Gladun // SCIENCE TIME, 2014. - No. 11. - P. 46 - 62.

3. Gladun L. A. Formation of methodological competencies in future special teachers: dissertation ... candidate of pedagogical sciences: 13.00.03 / Gladun Larisa Aleksandrovna. - Moscow, 2011 .-- 320 p.

4. Kuzmina N.V. Professionalism of pedagogical activity [Text] / NV Kuzmina, AA Rean. - SPb. : [b. and.]; Rybinsk: [b. and.], 1993. - 54 p.

5. Markova A.K. Psychology of teacher's work: book. for the teacher [Text] / A. K. Markova. - M.: Education, 1993 -- 192 p.

6. Mitina L.M. Psychology of labor and professional development of a teacher [Text]: textbook. manual for stud. universities, training. by special 031000 Ped. and psychol. / L. M. Mitina. - M.: Academy, 2004 --- 320 p.

7. Russian language in primary grades [Text]: theory and practice of teaching: textbook. allowance / M. S. Soloveichik [and others]; ed. M.S.Soloveichik. - M.: Education, 1993 .- 384 p.

8. Sarantsev G.I. Methodology of subject teaching methods [Text] / GI Sarantsev // Pedagogy, 2000. - No. 8. - P. 16 - 23.

9. Yakovleva I.M. Formation of professional competence of the teacher of oligophrenopedagogue [Text]: monograph / IM Yakovleva. - M.: Sputnik +, 2009 .- 220 p. 